\title{
Introduction of Enhanced Vision System and its Application for General Aviation
}

\author{
Ing. Roman Matyáš \\ Department of Air transport, Faculty of Transportation Science \\ CVUT in Prague \\ Prague, Czech Republic \\ matyarom@fd.cvut.cz
}

\begin{abstract}
Enhanced Vision System (EVS) technology has been developing since $1980 \mathrm{~s}$. The research itself has been mainly focused on controlling Unmanned Aerial Vehicles (UAVs). In this area, some methods were successfully tested, from take-off to landing. This paper is meant to be an introduction for further research and testing within general aviation area for use of EVS technology by high experienced as well as low experienced pilots in order to increase the level of safety during critical stages of flight.
\end{abstract}

Keywords-Enhanced Vision System; General Aviation; thermovision; IR cameras

\section{INTRODUCTION}

EVS technology has potentially high impact for wide range of usage across all the industries where vehicles are being driven or controlled by providing to the controller a visual aid which is important particularly in low visibility weather or during dark. This paper is focused on the aviation area, respectively on the general aviation. While commercial operators strictly comply with all safety measures published by respective authorities, private operators are in many cases just recommended to comply with them. Based on this, there are also some options for commercial operators. Connected to EVS problematics, operators using approved EVS shown on HeadUp-Display (HUD) favoring by reduced Decision Height or Minimum Descent Height (DH/MDH) to $100 \mathrm{ft}$ above threshold elevation (amendment to CFR Section 91.175 in USA in 2004). On the other hand, restricted budget of the private operators imply that not all recommended safety measures are implemented. This area of civil aviation is great spot for the idea of creation low cost device based on infrared technology for pilots and operators with limited financial resources.

We can divide aerial vehicles, regarding to the means of their control, to the autonomous and man-controlled ones. Creative research has been done in autonomous UAV industry using EVS for final phases of flight - approach and landing with use of IR cameras equipped with autonomous target recognition (ATR) systems.

Controlling aircraft during approach and landing is one of the most crucial stages of flight and requires continuous and accurate evaluation of aircraft attitude and its position relative to the obstacles and ground. This is the key element of its success. Not every time during flight operations there is nice weather with unlimited visibility, sometimes the weather conditions, especially the cloud base and visibility, creates so called marginal visual meteorological conditions (VMC). In that case, there is an enormous amount of stress put on unexperienced pilot during the approach phase of flight and landing. This corresponds to the distribution found in the Figure 1. Phases of high workload correspond with high accident rates. Weather and night time are contributing elements in those accidents.

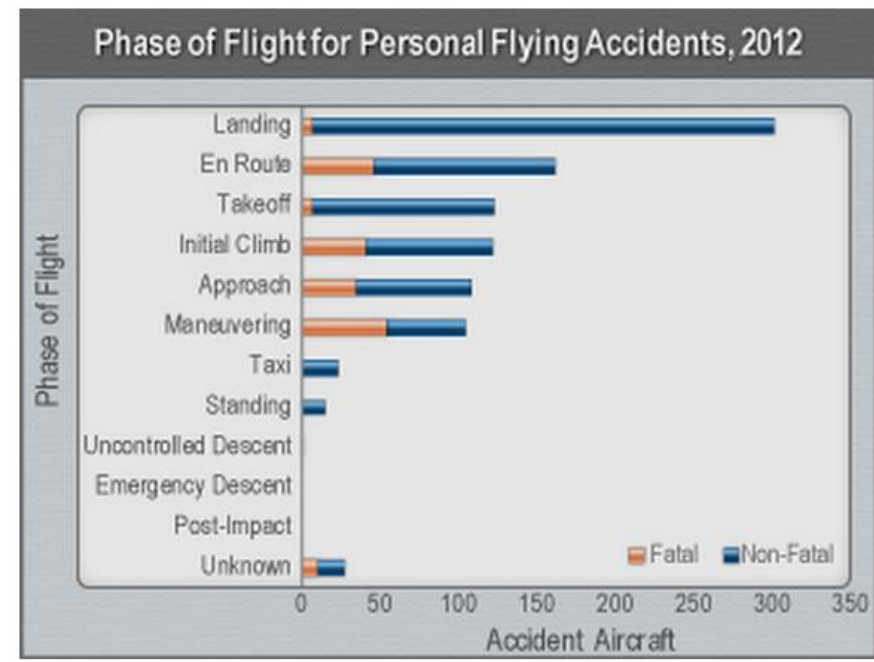

Figure 1. Distribution of General Aviation accidents in dependence to phase of flight for calendar year 2012 [1]

This fact is also reflected in the statistics of American Federal Aviation Administration (FAA) where general aviation has long and strong tradition. During calendar year 2014, the accident rate to 100,000 logged flight hours was 5,7 times higher in general aviation compare to commercial operations (incorporating commuter operations under 14 CFR Part 135 and airliners operating under 14 CFR Part 121) as could be seen in the Figure 2. Obviously, the general aviation has great potential of reducing those accident records and one of the courses is using Technologically Advanced Aircraft (TAA) equipped with high-tech tools such as Synthetic Vision System 


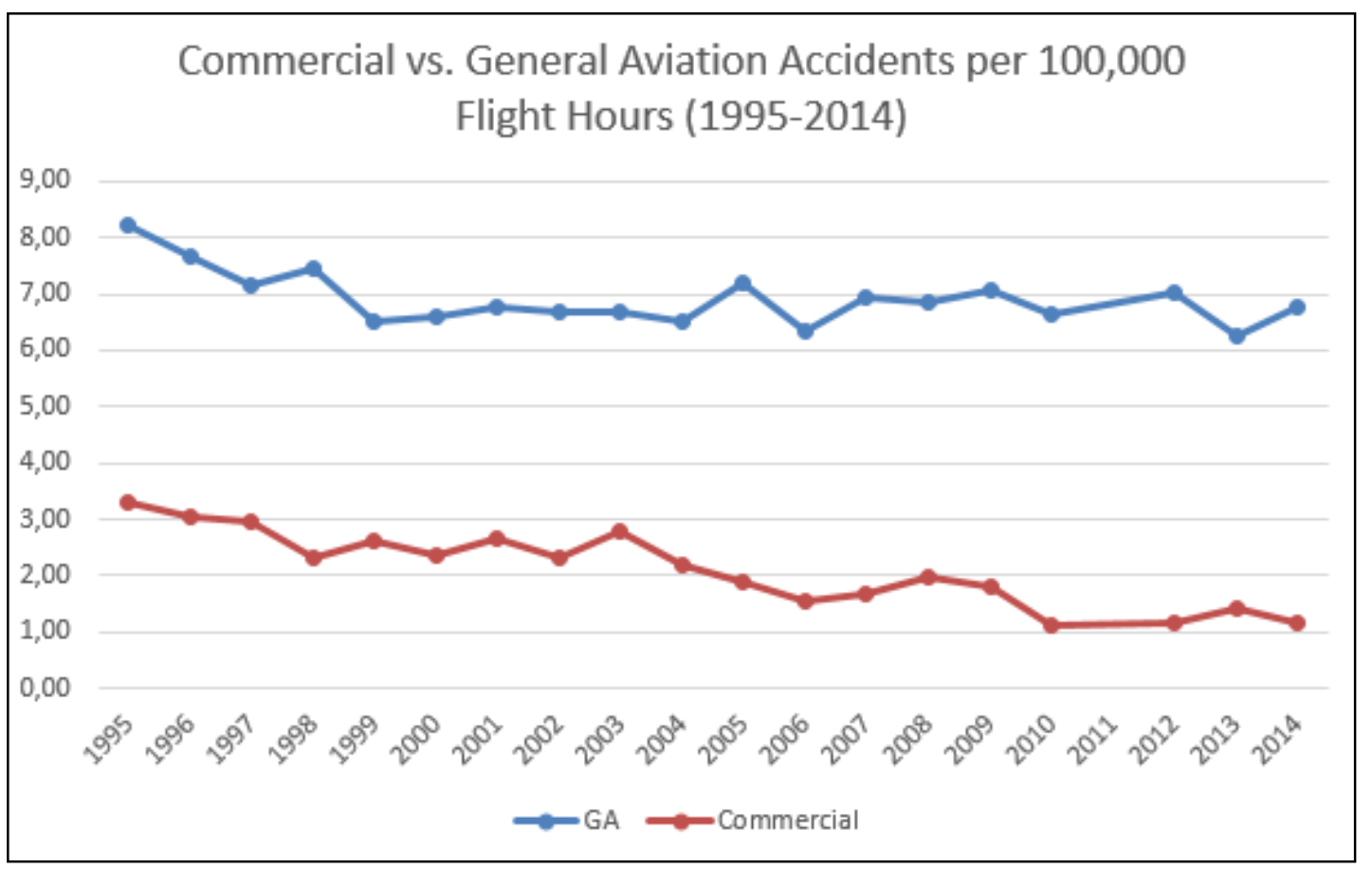

infra-red

sources. Regarding to their paper, the target of $5 \times 5 \mathrm{~m}$ must have only $1 \mathrm{~K}$ temperature difference to the ambient background. The results revealed that IR camera operating in spectral range of $8-12 \mu \mathrm{m}$ is able to increase the visibility from $610 \mathrm{~m}$ up to $2.4 \mathrm{~km}$ and visibility of $1.22 \mathrm{~km}$ up to $10.1 \mathrm{~km}$. For visibilities under $300 \mathrm{~m}$ there is no significant improvement achieved by using thermo vision equipment. This backings the idea to use infrared camera with thermal IR region of 8-12 $\mu \mathrm{m}$ as supportive device for VFR pilots and for private instrument pilots, who

Figure 2. Comparison of Commercial and General Aviation Accident rates per 100,000 flight hours between 1995 and 2014 (year 2011 is left blank due to incomplete data)

(SVS), EVS, and Electronic Stability Protection (ESP). TAAs had higher accident rates during 2003-2006 than GA fleet, mostly caused by poor training. Since 2007 when the biggest producer of TAAs transformed training syllabus the accident rate has downward tendency and in 2014 was approximately one half of GA average.

While pilots during VFR flights must fully rely on their eyes, instrument pilots have an advantage of radio navigational signal supporting them to follow correct flight path in both lateral and vertical plane. If we neglect the case of letting this radio-based signal lead the aircraft to the ground $(0 \mathrm{ft} \mathrm{DH})$ which is the case of general aviation, there exists period of ten or more seconds after penetrating cloud layer during which even instrument pilots need visual reference of runway or its surroundings to execute the landing maneuver right and safe. And those last few seconds may be critical in low visibility conditions. For this short but crucial period is supportive device important, it increases probability of successful landing and level of safety.

\section{BACKROUND}

The idea of using IR sources for navigational and landing purposes is dated to some late 1950s and early 1960s. Butler in 1962 published the principle of design of the first infra-red source giving high flux density. He followed research of Cade (1959) and pair of Fioch and Dahl who described the idea of installation of such sources in the surface of the runway edges to provide landing aid for aircraft.

Beier and Gemperlein in 2004 tested the detection range of IR camera for different meteorological conditions without any both operate in visibilities from 0.6 to $1.5 \mathrm{~km}$.

Yang Gui and his team in 2012 focused on UAV landing using infrared lapms for accurate execution of landing manoeuvre. Using a visible light camera with a $940 \mathrm{~nm}$ optical filter for detecting signal of four infrared light emitting diode (LED) lamps with emission wavelengths of $940 \mathrm{~nm}$ placed behind ideal landing site or runway is another approach. Camera has also integrated processor for digital data evaluation in order to land automatically. This airborne vision-based navigational method achieved great results while using non IR camera.

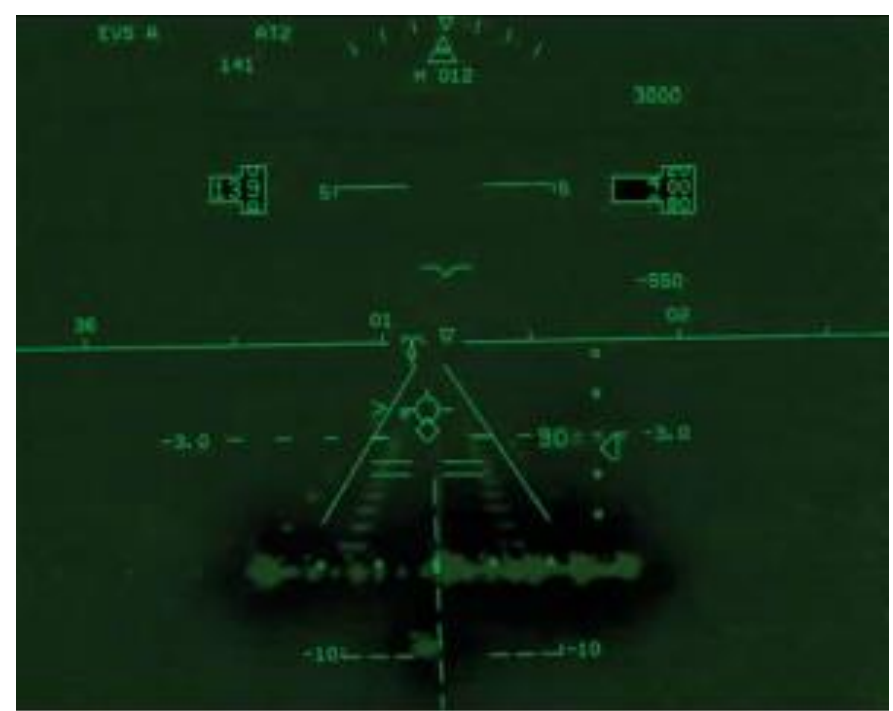

Figure 3. Combined SVS/EVS Image displayed on HUD [6]

Another method for automatic landing of UAV was tested by Shang et al. who proposed a method of recognizing runway in the image of camera. 
Etinger and Nechyba were using roll and pitch angles of UAV, where roll angle was obtained by extracting the horizon in the image.

$\mathrm{Li}$ et al. used adaptive Hough fitting method to estimate the UAV position in accordance with the three runway lines their shapes and positions.

A team

of

Honeywell,

Gulfstream Aerospace

Corporation and

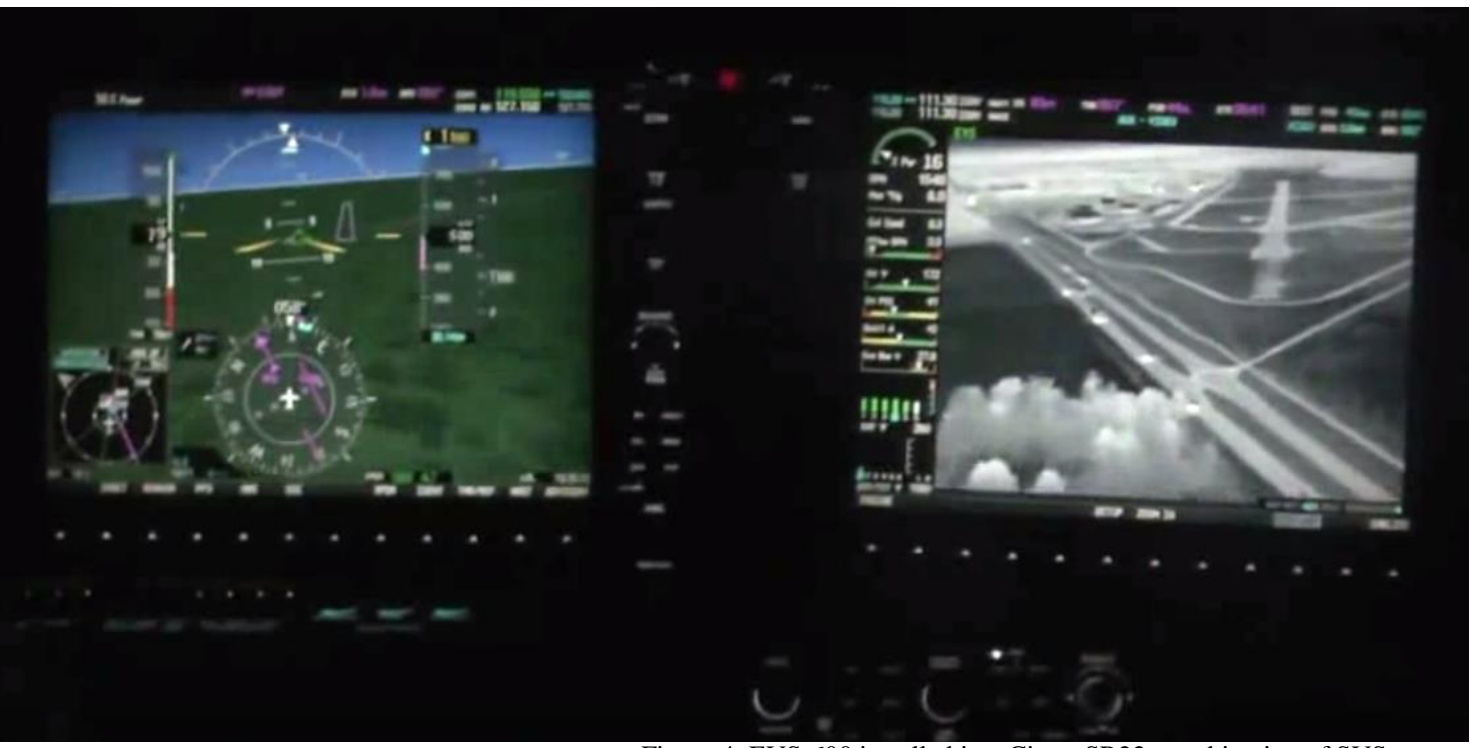

NASA personnel were evaluating the usage of EVS in combination with SVS and HUD used by test crews. They conducted several flight tests with Kollsman II EVS sensor during 2011 with potentially valuable results for developing EVS based low cost device. Especially evaluation of HDD procedures evaluation, precipitation's degrading ability of EVS and non-homogeneous weather adverse effect as well as radar altitude based flare cue has not significant effect on landing performance of crew. Important factor remains on proper crew procedures.

\section{USAGE OF EVS IN GA NOWADAYS}

The EVS technology were used in military first. As some of those information are still not available, the proved evidence states that still in 2000 Turret-FLIR (Forward-Looking InfraRed) gimbal was used on C141 and C-130 aircraft for military Special Operations missions in the USA. This system needed to be operated by additional crew member.

Gulfstream uses for its new G500 and G600 models Kollman's EVS SP models - high resolution, cooled infrared sensor that provides imagery directly on a HUD.

The Max-Viz EVS-600 technology, on the other hand, uses uncooled microbolometer technology to attain equivalent performance with prices much lower compare to cooled sensors. This EVS-600 is nowadays installed into GA propeller driven aircraft with speeds up to $250 \mathrm{kt}$.

\section{CONCLUSION}

As was discussed above, today we know number of manners based on infrared technology that enhance visual references. Furthermore, some of them are used today in general aviation, however, the price of those devices is still high enough to prevent them of spreading throughout GA industry. The research and development of low cost device is a great challenge which could bring safety of flight to the higher level, especially private operations where it has huge potential.

Figure 4. EVS-600 installed in a Cirrus SR22, combination of SVS on Primary Flight Display (PFD) and EVS on Multi-Function Display MFD [7].

\section{ACKNOWLEDGMENT}

This paper was supported by the Grant Agency of the Czech Technical University in Prague, grant No. SGS15/172/OHK2/2T/16.

\section{REFERENCES}

[1] NTSB, Summary of US Civil Aviation Accidents for Calendar Year 2012, available online, http://www.ntsb.gov/investigations/data/Pages/2012\%20Aviation\%20Ac cidents\%20Summary.aspx

[2] Kurt Beier and Hans Gemperlein, Simulation of infrared Detection Range at Fog Conditions for Enhanced Vision Systems in Civil Aviation. Aerospace Science and Technology 8 (2004) 63-71

[3] Butler W. H., An infra-red Source Giving High Flux Density, British Journal of Applied Physics, vol. 13, 1962, pp 227-230

[4] Jeff Guell, FLILO (FLying Infrared for Low-level Operations) - an Enhanced Vision System, IEEE AES Systems Magazine, September 2000

[5] Yang Gui et al., Airborne Vision-Based Navigation Method for UAV Accuracy Landing Using Infrared Lamps, J Intell Robot Syst (2013) 72:197-218

[6] Kevin J. Shelton, Lynda J. Kramer, Kyle Ellis, and Dr. Sherri A. Rehfeld, Synthetic And Enhanced Vision Systems (Sevs) For Nextgen Simulation And Flight Test Performance Evaluation, 31st Digital Avionics Systems Conference, October 14-18, 2012

[7] Forward Vision EVS Systems, Pirep: Cirrus EVS, available online: https://www.youtube.com/channel/UCLIhUxWoTf_O15rH8txNGcA, 2011

[8] Astonics Max-Viz, http://www.max-viz.com/\#!faq/c6pz

[9] Kraus, J., Visokai, V.: Analysis of Landing in IMC at VFR Aerodromes. Acta Avionica. 2015, vol. 17, no. 1, p. 47-52. ISSN 1335-9479.

[10] Vittek, P., Němec, V., Straková, E.: New Approach to Aviation Safety. In New Trends in Aviation Development. Jilemnického 4/A, 08001 , Prešov: Pavol Štáhlavský - Akcent Print, 2010, p. 226-230. ISBN 97880-553-0475-5. 